\title{
Patients' perceptions of their participation in a clinical trial for postoperative Crohn's disease
}

ED Kennedy $\mathrm{MD}^{1}$, JE Blair RN ${ }^{1}$, R Ready BScN ${ }^{2}$, BG Wolff MD FACS ${ }^{2}, \mathrm{AH}_{\text {Steinhart MD FRCPC }}^{3}$, PW Carryer MD FACP ${ }^{4}$, RS McLeod MD FRCSC ${ }^{1}$

ED Kennedy, JE Blair, R Ready, et al. Patients' perceptions of their participation in a clinical trial for postoperative Crohn's disease. Can J Gastroenterol 1998;12(4):287-291.

OBJECTIVE: To explore patients' perceptions of their participation in a randomized controlled trial.

PATIENTS AND METHODS: A 27-item questionnaire was mailed to all patients who participated in a randomized controlled trial that determined the effectiveness of mesalamine in preventing the recurrence of Crohn's disease postoperatively.

RESULTS: The response rate was 66\% (99 of 149). Fifty-five per cent of the patients felt that they received better medical care than they otherwise would have and 53\% liked taking the medication. Sixty-eight per cent of the patients did not feel that annual colonoscopy was too frequent and $81 \%$ felt that the time commitment did not significantly interfere with their job or other activities. Seventy-five per cent and $62 \%$ of the patients would have liked more information and education, respectively, about Crohn's disease incorporated into the trial. Although $91 \%$ of the patients would agree to participate in a future randomized controlled trial comparing medical therapies, only $44 \%$ would agree to participate in a future randomized controlled trial comparing medical with surgical therapies.

CONCLUSIONS: The majority of patients were satisfied with their participation in the trial. A large proportion of the patients would participate again but would like more information and education incorporated into the trial. Furthermore, post-trial questionnaires may be helpful in the design of future trials.

Key Words: Crohn's disease, Patient preference, Randomized controlled trial
Perception qu'ont les patients de leur participation à un essai clinique sur la maladie de Crohn en post-opératoire

OBJECTIF : Étudier la perception qu'ont les patients de leur participation à un essai contrôlé randomisé.

MATÉRIEL ET MÉTHODES : Un sondage de 27 questions a été posté à tous les patients qui ont participé à un essai randomisé contrôlé en vue de déterminer l'efficacité de la mésalamine dans la prévention de la récidive de la maladie de Crohn après une chirurgie.

RÉSULTATS : Le taux de réponses a été de 66 \% (99 sur 149). Cinquante-cinq pour cent des patients ont estimé avoir reçu un meilleur traitement médical et $53 \%$ ont apprécié prendre le médicament. Soixante-huit pour cent des patients n'ont pas estimé que la fréquence annuelle de la colonoscopie était exagérée, 81 \% ont déclaré que les contraintes de temps n'avaient pas significativement nuit à leur travail ou autres activités. Soixante-quinze pour cent et $62 \%$ des patients respectivement auraient aimé plus de renseignements et de formation sur la maladie de Crohn dans le cadre de l'essai. Bien que $91 \%$ des patients aient déclaré qu'ils accepteraient de participer à un autre essai randomisé contrôlé éventuellement pour comparer les traitements médicaux, 44 \% seulement accepteraient de participer à un essai randomisé contrôlé comparant un traitement médical à un traitement chirurgical. CONCLUSIONS : La majorité des patients se sont dits satisfaits de leur participation à l'essai. Une forte proportion de patients y participeraient de nouveau, mais préféreraient plus d'information et de formation dans le cadre de l'essai. De plus, l'administration d'un questionnaire une fois l'étude terminée pourrait être utile à l'élaboration de futures essais.

Departments of ${ }^{1}$ Surgery and ${ }^{2}$ Medicine, Mount Sinai Hospital, University of Toronto, Toronto, Ontario; Departments of ${ }^{3}$ Colorectal Surgery and ${ }^{4}$ Medicine, Mayo Clinic, Rochester, Minnesota

Correspondence: Dr RS McLeod, Mount Sinai Hospital, 600 University Avenue, Suite 449, Toronto, Ontario M5G 1X5. Telephone

416-586-8347, fax 416-586-8644, e-mail rmcleod@mtsinai.on.ca

Received for publication January 29, 1998. Accepted April 30, 1998 
A lthough it is well accepted that patients who participate in clinical trials are inherently different from those who do not participate, few surveys have assessed the perceptions of these patients (1-4). Since it is these patients who are more likely to participate in future trials, a better understanding of their perceptions of a clinical trial is important.

Therefore, a survey of the patients who participated in a clinical trial was undertaken to determine whether mesalamine is effective in preventing postoperative recurrence of Crohn's disease (5).

Although this survey explored the patients' perceptions about different aspects of the trial, the main objective was to identify aspects of the trial the patients felt could be improved.

It was thought that once strategies to improve trials were identified, further assessment and implementation of these strategies may lead to increased accrual rates and decreased attrition rates in future clinical trials.

\section{PATIENTS AND METHODS}

Patient recruitment: Patients who had previously participated in a randomized controlled trial determining whether mesalamine is effective in preventing the postoperative recurrence of Crohn's disease were eligible to participate in the study (5). During this trial, all participants received 12 tablets/day (mesalamine $1.5 \mathrm{~g}$ bid or placebo) and underwent colonoscopy and/or other endoscopic or radiological examinations annually. The maximum follow-up was 72 months, with mean follow-up of approximately 30 months. For this survey, 159 of the 163 participants in the trial were mailed questionnaires approximately one year after the completion of the trial. Four patients were lost to follow-up.

Study design: A 27-item questionnaire was developed. Sixteen items were specific statements about the trial and were framed in a positive manner. Patients evaluated the degree to which they disagreed or agreed with these statements on a five-point Likert scale, ' 1 ' indicating 'strongly disagree' and '5' indicating 'strongly agree'. Nine items were statements

TABLE 1

Patients' perceptions of different aspects of the trial

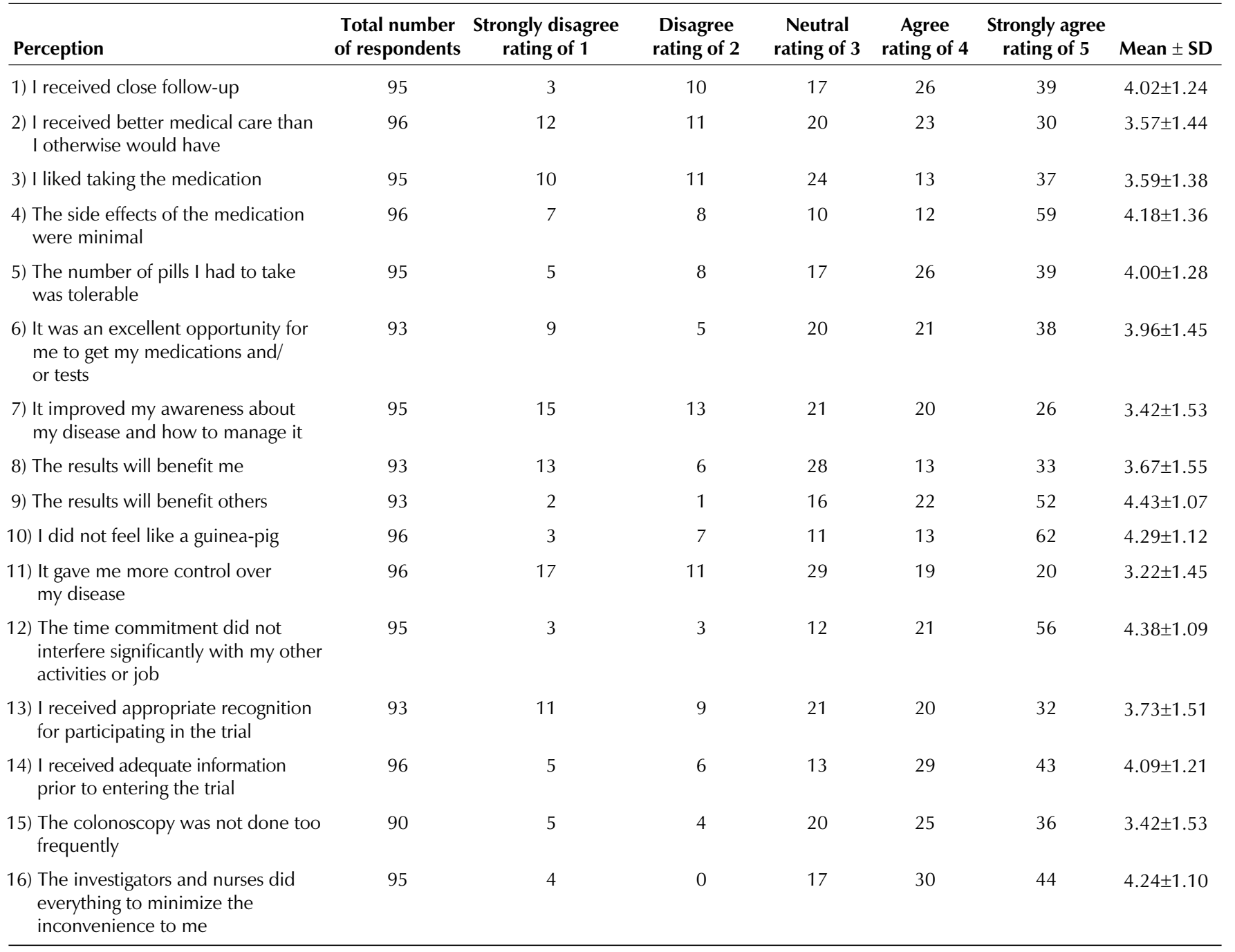


TABLE 2

Patients' perceptions of aspects of the trial to be improved

\begin{tabular}{|c|c|c|c|c|c|c|c|}
\hline Perception & $\begin{array}{l}\text { Total number of } \\
\text { respondents }\end{array}$ & $\begin{array}{l}\text { Strongly disagree } \\
\text { rating of } 1\end{array}$ & $\begin{array}{c}\text { Disagree } \\
\text { rating of } 2\end{array}$ & $\begin{array}{l}\text { Neutral } \\
\text { rating of } 3\end{array}$ & $\begin{array}{c}\text { Agree } \\
\text { rating of } 4\end{array}$ & $\begin{array}{l}\text { Strongly agree } \\
\text { rating of } 5\end{array}$ & Mean \pm SD \\
\hline $\begin{array}{l}\text { 1) I would have preferred more } \\
\text { information about the trial prior } \\
\text { to its commencement }\end{array}$ & 95 & 7 & 9 & 36 & 14 & 30 & $3.60 \pm 1.31$ \\
\hline $\begin{array}{l}\text { 2) I would have preferred more } \\
\text { information about the trial } \\
\text { while it was in progress }\end{array}$ & 96 & 3 & 1 & 20 & 31 & 41 & $4.16 \pm 1.05$ \\
\hline $\begin{array}{l}\text { 4) I would have liked to receive } \\
\text { better medical care during the } \\
\text { trial }\end{array}$ & 95 & 35 & 17 & 29 & 8 & 6 & $2.44 \pm 1.46$ \\
\hline $\begin{array}{l}\text { 5) There should have been more } \\
\text { financial incentives }\end{array}$ & 95 & 44 & 9 & 22 & 9 & 11 & $2.45 \pm 1.63$ \\
\hline $\begin{array}{l}\text { 8) The investigations should have } \\
\text { been performed less often }\end{array}$ & 91 & 32 & 23 & 29 & 6 & 1 & $2.46 \pm 1.54$ \\
\hline $\begin{array}{l}\text { 9) The trial should have been } \\
\text { shorter in duration }\end{array}$ & 93 & 27 & 19 & 33 & 5 & 9 & $2.68 \pm 1.54$ \\
\hline
\end{tabular}

pertaining to improvements that could be made to the trial. Again, patients evaluated the degree to which they disagreed or agreed with these statements on a five-point Likert scale. The remaining two items were questions regarding future participation in clinical trials and were answered as 'yes' or 'no'. The questionnaires were mailed with a stamped, self-addressed envelope. A follow-up reminder was mailed to all of the patients three weeks after the initial mailing. Data from the questionnaires were entered into a computerized database. Data analysis was performed using Excel (Microsoft, Washington) and SAS software (SAS Institute, North Carolina). The frequency distribution as well as the mean and SD for each item are presented.

\section{RESULTS}

Of the 159 questionnaires distributed, 10 were returned with no forwarding address. Ninety-nine of the remaining 149 participants $(66 \%)$ responded to the questionnaire.

During the trial, participants were subgrouped according to nationality, compliance and disease status. Compliant patients were patients who took the medication (or placebo) for the duration of the trial. The mean compliance rate for this group, assessed by pill count, was $81 \%$. Noncompliant patients were patients who stopped taking the medication (or placebo) before the trial was completed. Disease status refers to whether patients had a symptomatic recurrence during the course of the trial. Symptomatic recurrence was defined as symptoms of recurrence that were proven radiologically or endoscopically.

As expected, significantly more compliant patients than noncompliant patients responded to the questionnaire $(72 \%$ versus $53 \%, \mathrm{P}=0.03)$. There was no significant difference in the response rates by nationality ( $74 \%$ of Canadians versus $62 \%$ Americans, $\mathrm{P}=0.16$ ) or by disease status (79\% with recurrence versus $61 \%$ with no recurrence, $\mathrm{P}=0.13)$.

Not surprisingly, 91\% (84 of 92) of the patients would agree to participate in a future randomized controlled trial comparing two medical therapies. However, only 44\% (37 of 84) of the patients would agree to participate in a future randomized controlled trial comparing medical with surgical therapy.

The results of the 16 items pertaining to the patients' perceptions of the different aspects of the trial are shown in Table 1. Patients generally had positive views about the trial, which is not surprising because this may be one of the reasons they originally agreed to participate in the trial. It is interesting, however, that even though the trial was a maximum of six years in duration, 68\% (61 of 90) of the patients did not feel that colonoscopy was performed too frequently and $81 \%$ (77 of 95) did not feel that the time commitment significantly interfered with their job or other activities. Seventy-four per cent ( 71 of 96) of the patients felt that the side effects of the medication were minimal and 53\% (50 of 95) did not dislike taking their medication despite having to take 12 tablets/day.

Many patients felt that there were benefits to their participation. Fifty-five per cent (53 of 96) of the patients felt that they received better medical care than they otherwise would have and $63 \%$ felt that it was an excellent opportunity 
TABLE 3

Comparison of patients' perceptions of various trials

\begin{tabular}{|c|c|c|c|c|c|}
\hline Perception & \multicolumn{5}{|c|}{ Study (reference) } \\
\hline Benefit to me & $49 \%$ & $84 \%$ & $59 \%$ & $95 \%$ & $25 \%$ \\
\hline Benefit to others & $80 \%$ & $65 \% *$ & $73 \%$ & $92 \%$ & $32 \%$ \\
\hline Receive better medical care & $55 \%$ & $74 \%$ & $72 \%$ & $90 \%$ & \\
\hline $\begin{array}{l}\text { Learned more about medical } \\
\text { condition }\end{array}$ & $48 \%$ & $45 \%$ & $54 \%$ & $82 \%$ & \\
\hline $\begin{array}{l}\text { Would probably participate } \\
\text { in another similar study }\end{array}$ & $91 \%$ & $60 \%$ & $51 \%$ & $40 \%^{+}$ & $87 \%$ \\
\hline
\end{tabular}

AMIS Aspirin Myocardial Infarction Study; BHAT Beta-Blocker Heart Attack Trial; CCCT Colon Cancer Chemoprevention Trial; SOLVD Studies Of Left Ventricular Dysfunction. *When asked why they decided to participate, $74 \%$ of the patients stated they decided to participate to "help themselves" and $65 \%$ "to help others". A total of $84 \%$ stated that they benefitted from participating in the study; ${ }^{\dagger}$ These patients did not participate in a placebo controlled trial. Forty per cent would agree to participate in a similar trial, $20 \%$ would agree to participate in a placebo controlled trial and $10 \%$ would participate in a similar trial if out-of-pocket expenses were not paid for

to receive medicine and/or tests. Forty-nine per cent (46 of 93) of the patients felt that the results would benefit them, and $48 \%$ (46 of 95 ) and $41 \%$ (39 of 96 ) felt that they had improved awareness and more control, respectively, over their disease.

Table 2 lists the results of items regarding areas for improvement. The majority of the patients wanted more information (72 of 96) and education (59 of 95) during the trial. Most patients did not think that the study should have been shorter (46 of 93), that the investigations should have been performed less often (55 of 91) or that there should have been more financial incentives (53 of 95).

Because multiple $t$ tests were used for the subgroup analysis, $\mathrm{P}<0.05$ was considered to show a trend rather than a statistical difference. All trends found were in the direction that was expected. American patients were more likely than the Canadian patients to feel that their participation was an excellent opportunity to receive medications, tests or both $(\mathrm{P}=0.046)$. Patients with no recurrent disease were more likely than those with recurrent disease to feel that they received better medical care $(\mathrm{P}=0.008)$ and that they gained more control over their disease $(\mathrm{P}=0.045)$. Noncompliant patients were less likely than compliant patients to like taking the medication $(\mathrm{P}=0.002)$ and to agree that the medication's side effects were minimal $(\mathrm{P}=0.008)$. Noncompliant patients were also more likely than compliant patients to feel like a guinea-pig $(\mathrm{P}=0.045)$, that investigations should be done less frequently $(\mathrm{P}=0.02)$ and that the trial should be shorter in duration $(\mathrm{P}=0.02)$.

\section{DISCUSSION}

The major limitation of this study is the response rate of $66 \%$, which, although considered acceptable, is quite low. Because it is likely that the responders and the nonresponders had different perceptions about the trial, the results must be interpreted with some caution. Unfortunately, because it was predetermined that the questionnaire had to be anonymous to obtain answers that were as honest as possible, this disallowed follow-up of nonresponders.

Despite this limitation, the results of this survey are of value because they provide information about what aspects of the trial the patients perceived as positive and negative, and what aspects they would like improved. This information may be helpful in the planning of future trials because it is these patients who are likely to participate in future trials, as supported by our result that $91 \%$ of the patients would agree to participate in future randomized controlled trial comparing two medical therapies.

Because it was expected that the majority of the patients would perceive most aspects of the trial as positive, the most valuable part of our study was related to suggestions for improvement. The majority of patients who participated in the trial felt that the time commitment did not significantly interfere with their other activities and/or job, which is consistent with the results of other published studies $(1,3-5)$ (Table 3 ). This finding suggests that the time commitment factor may not play a major role in influencing patients' participation in trials.

Seventy-nine per cent of our patients did not mind that there was no financial reimbursement and 91\% would agree to participate in a similar trial. These results are similar to those from a study that looked at the perception of patients in the Aspirin Myocardial Infarction Study (AMIS) and the Beta-Blocker Heart Attack Trial (BHAT), both of which were randomized, placebo controlled trials (1). The participants in both trials also received no financial incentives, and $60 \%$ of the AMIS participants and $51 \%$ of the BHAT participants agreed to participate in a similar future trial (Table 3 ). However, the results of two other studies, one American and one Spanish, showed that 'experienced' volunteers were more likely than 'nonexperienced' volunteers to participate solely for financial rewards $(3,6)$. 
In our study, the majority of patients felt that more education about their disease should be given before and during the trial. This is interesting especially when analyzed in conjunction with the result that only $49 \%$ of the patients felt they benefitted from participating in the trial and only $40 \%$ felt that their participation gave them control over their disease. These results are similar to those from oncology patients participating in nonrandomized chemotherapy trials who were surveyed prospectively through their participation in the trial (2). Participants reported receiving less information by health care professionals as the trial progressed, which left them feeling out of control and uncertain of the future. At the completion of the trial, participants experienced a sudden decline in the contact and attention to which they had grown accustomed, which left some of them feeling out of control, let-down and helpless.

Although results of the studies of patients cannot be directly compared, most patients who felt that they learned more about their disease were more likely to feel that they benefitted from their participation in the trial (Table 3). An exception may be those in the AMIS study because this study consisted of only $10 \%$ of the patients who actually participated in the trial. Therefore, patients may not agree to participate in trials solely for altruistic reasons. Other reasons such as education may also be important. Strategies to educate patients better about their disease and give them tools to deal more independently with their disease appear to be important. These strategies may not only include a research nurse, but also newsletters and group meetings. Fur-

\section{REFERENCES}

1. Mattson NM, Curb JD, McArdle R, AMIS and BHAT Research Groups. Participation in a clinical trial: the patients' point of view. Controlled Clin Trials 1985;6:156-67.

2. Cox K, Avis M. Psychosocial aspects of participation in early anticancer drug trials. Cancer Nurs 1996;19:177-86.

3. Hudmon KS, Stoltzfus C, Chamberlain RM, Lorimor RJ, Steinbach G, Winn RJ. Participants' perceptions of a phase I colon cancer chemoprevention trial. Controlled Clin Trials 1996;17:494-508.

4. Henzlova MJ, Blackburn GH, Bradley EJ, Rogers WJ for the SOLVD Close-out Working Group. Patient perception of a long term clinical trial: experience using a close-out questionnaire in the Studies Of Left thermore, at the completion of the trial, patients may feel let-down, and continuing support after the trial may be necessary.

In our study, although only $49 \%$ of the patients felt that they benefitted from their participation in the trial, $91 \%$ of the patients would agree to participate in a future trial comparing two medical therapies. These results are not dissimilar to those from the other surveys presented in Table 3; however, our patient population, nature of the disease (chronic and benign) and treatment, health care system and timing of the questionnaire relative to the closure of the trial and unblinding may be reasons for slightly different trends.

\section{CONCLUSIONS}

The results of this survey suggest that patients who volunteer to participate in a clinical trial are satisfied with most elements of the study design. Although these patients may agree to participate for altruistic reasons, other factors such as education may also be important incentives motivating these patients to participate.

Because patients who have previously participated in a clinical trial are more likely to participate in future trials, it is important to explore their perceptions to determine whether strategies to improve patient satisfaction in a clinical trial exist. Further studies assessing the effectiveness of these strategies will then be needed to see whether these strategies lead to increased accrual and decreased attrition rates. In summary, post-trial surveys may prove to be useful in the planning of future trials.

Ventricular Dysfunction (SOLVD) trial. Controlled Clin Trials 1994;15:284-93.

5. McLeod RS, Wolffe BG, Steinhart AH, et al. Prophylactic 5-aminosalicyclic acid decreases postoperative recurrence of Crohn's disease. Gastroenterology 1995;109:404-13.

6. Aby JS, Pheley AM, Steinbery P. Motivation for participation in clinical trials of drugs for the treatment of asthma, seasonal allergic rhinitis, and perennial nonallergic rhinitis. Ann Allergy Asthma Immunol 1996;76:348-53.

7. Bigorra J, Banos JE. Weight of financial reward in the decision by medical students and experienced healthy volunteers to participate in clinical trials. Eur J Clin Pharmacol 1990;38:443-6. 


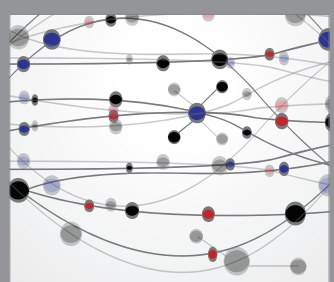

The Scientific World Journal
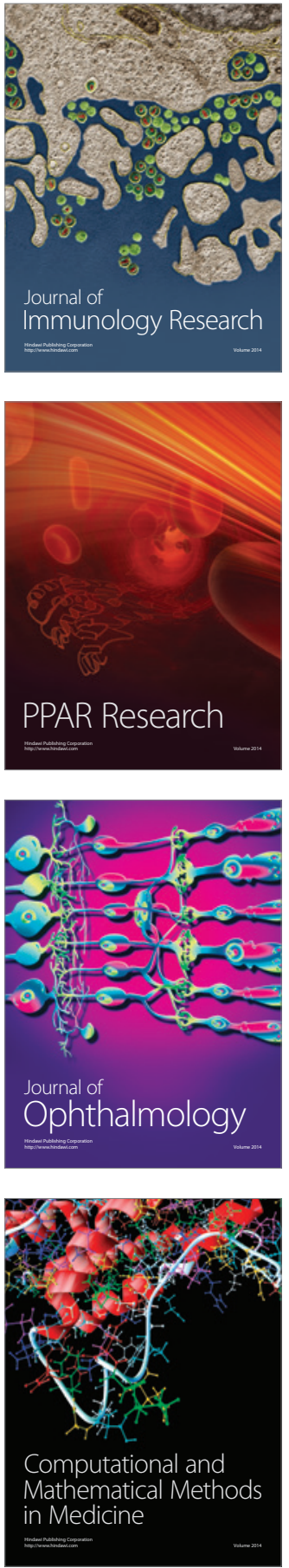

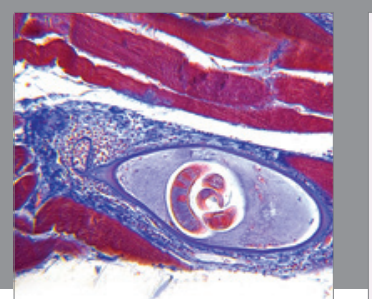

Gastroenterology Research and Practice

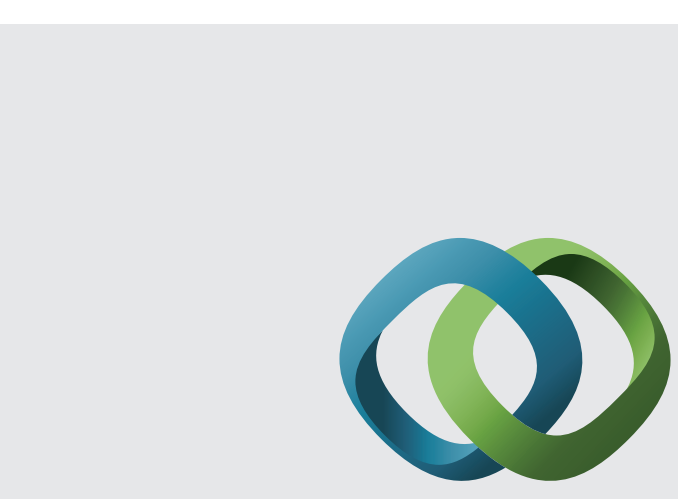

\section{Hindawi}

Submit your manuscripts at

http://www.hindawi.com
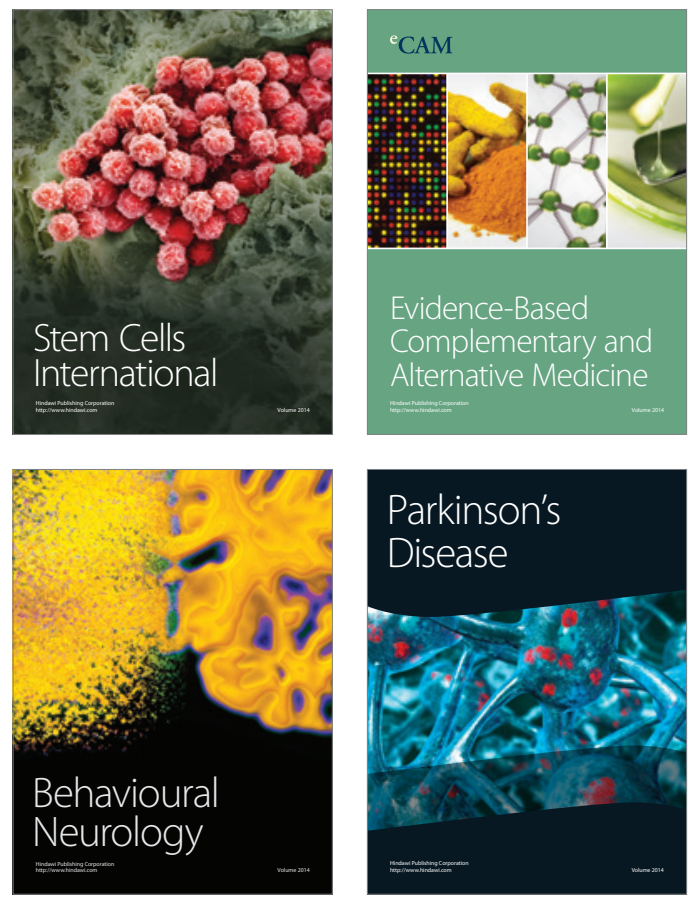
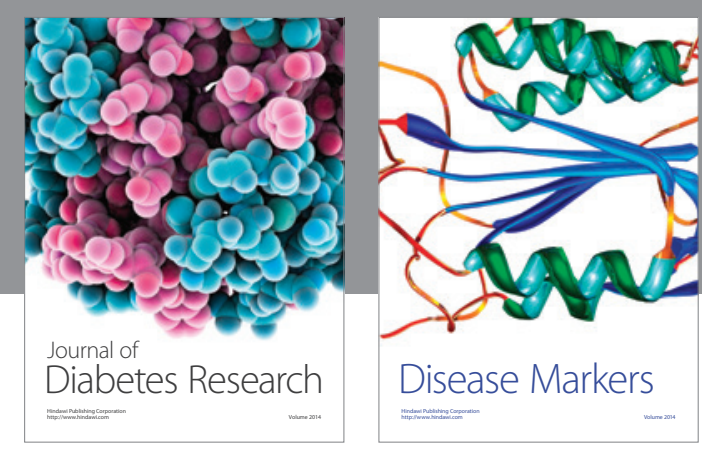

Disease Markers
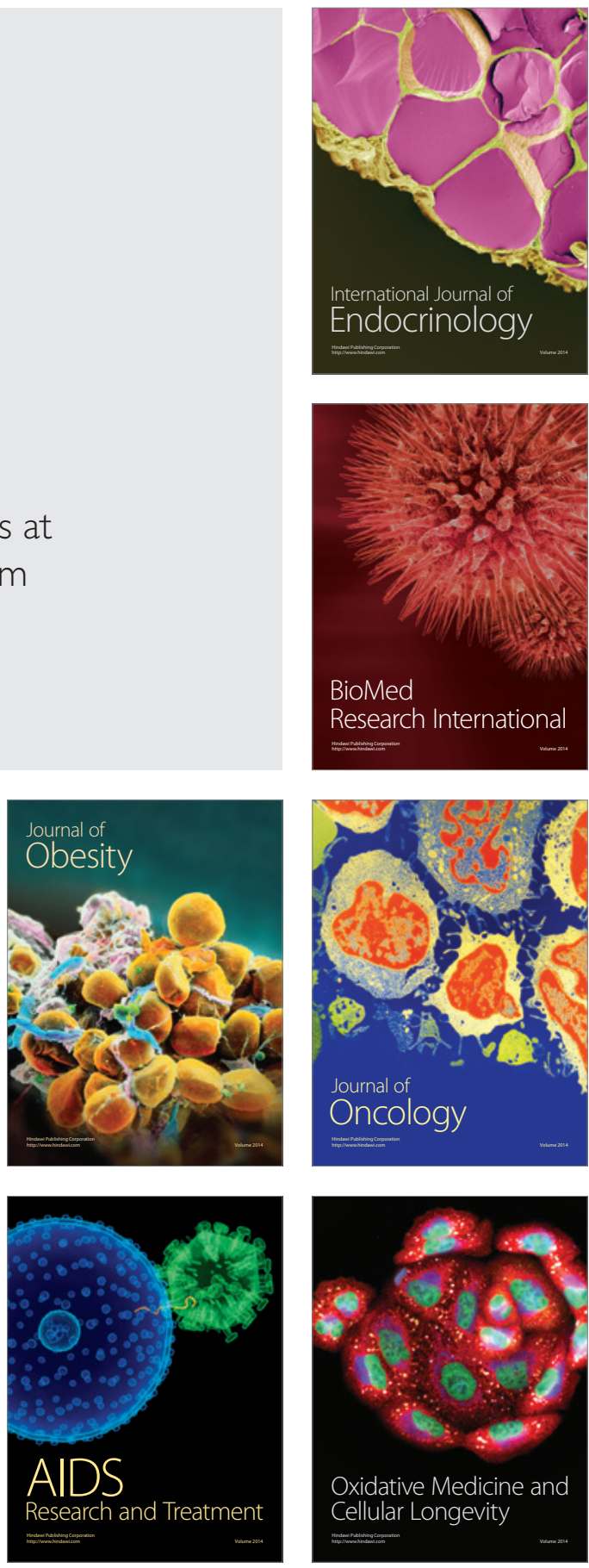